trials of mainly unopposed oestrogen in postmenopausal women appear to show highly significant reductions in both cardiovascular and all cause mortality from samples of a similar size to those of the major primary and secondary trials of lipid lowering drugs. ${ }^{12-15}$ These results too deserve further evaluation by controlled clinical trials. But meanwhile the lack of evidence of significant reductions in all cause mortality by lipid lowering drugs, ${ }^{3+16}$ particularly in primary prevention trials, indicates that any favourable effect of lipid-lowering drugs on all cause mortality is at best small and of only marginal benefit to the individual. At present the cost-benefit uncertainties generated by the WHO clofibrate trial and its successors emphasise the importance of restricting the use of hypolipidaemic drugs to patients with established vascular disease and hyperlipidaemia or to asymptomatic patients with severe hyperlipidaemia at high risk of premature vascular disease where dietary measures have been ineffectual.

\section{MATTHEW G DUNNIGAN}

Consultant Physician, Stobhill General Hospital,

Glasgow G21 3UW
1 Committee of Principal Investigators. WHO cooperative trial on primary prevention of ischaemic heart disease with clofibrate to lower serum cholesterol: final mortality follow-up. Lance 1984;ii:600-4

2 Committee of Principal Investigators. WHO cooperative trial on primary prevention of ischaemic heart disease with clofibrate to lower serum cholesterol: mortality follow-up. Lancet 1980;ii:379-85

3 Muldoon MF, Manuck SB, Matthews KA. Lowering cholesterol concentrations and mortality: a quantitative review of primary prevention trials. $B M \mathcal{F}$ 1990;301:309-13.

Davey-Smith G, Pekkanen J. Should there be a moratorium on the use of cholesterol lowering drugs? BMF 1992;304:431-3.

Coronary drug project research group. Clofibrate and niacin in coronary heart disease. $7 A M A$ 1975;231:360-81.

6 Carlson LA, Rosenhamer G. Reduction of mortality in the Stockholm ischaemic heart disease secondary prevention study by combined treatment with clofibrate and nicotinic acid. secondary prevention study by

7 Roussouw JE, Lewis B, Rifkind BM. Mortality experience in cholesterol-reduction trials. N

8 O'Brien BJ. Cholesterol and coronary heart disease: consensus or controversy? London: Office of Health Economics, 1991:63.

9 Bradford RH, Shear CL, Chremos AN, Dujoune C, Downton M, Franklin FA, et al. Expanded clinical evaluation of lovastatin (EXCEL) study results. I. Efficacy in modifying plasma lipoproteins and adverse event profile in 8245 patients with moderate hypercholesterolaemia. Arch Intern Med 1991;151:43-9.

10 Tobert JA. The cholesterol controversy. BMf 1992;304:713.

11 Reckless JPD. The cholesterol controversy. BMJ 1992;304:712.

12 Belchetz. P. Hormone replacement treatment. BMf 1989;298:1467.

13 Mishell DR. Estrogen replacement therapy: an overview. Am f Obstet Gynecol 1989;161:1825-7.

4 Knopp RH. Estrogen replacement therapy for reduction of cardiovascular risk in women. Current Opinion in Lipidology 1991;2:240-7.

15 Barrett-Connor E, Bush TL. Estrogen and coronary heart disease in women. JAMA 1991;265: 1861-7.

16 Raunskov U. Cholesterol lowering trials in coronary heart disease: frequency of citation and outcome BMF 1992;305:15-9.

\title{
Medicine and torture
}

\section{A new BMA report makes clear doctors' responsibilities for human rights}

Six years after the BMA's Torture Report ${ }^{1}$ comes Medicine Betrayed,$^{2}$ which gives a detailed account of doctors' participation in abuses of human rights. The report, the product of a two year study by a BMA working party, covers topics ranging from the illegal and outrageous (torture) through the judicial and outrageous (punishments such as amputations) to the difficult and ethically perplexing (hunger strikes and providing evidence in capital punishment trials). In addition the report discusses the mechanisms that allow people, particularly doctors, to participate in torture. ${ }^{3}$

Unfortunately, the evidence that doctors examine and resuscitate victims of torture and issue false death certificates is irrefutable. While acknowledging that doctors may come under strong pressure to compromise their ethics, the report points out that some doctors collaborate willingly. Some begin with the good intention of helping a person but end up by aiding and abetting the torturer, as part of a penal or judiciary system (in corporal punishment), or as an administrative tool removing the traces of torture (by issuing false or incomplete medical or death certificates).

The extent to which doctors participate voluntarily varies: fear of the consequences of refusal and peer group pressure may partly explain why some doctors take part. Ignorance of human rights and indifference reinforce these mechanisms. Doctors working in institutions where people are held against their will (such as prisons and mental hospitals) and in potentially coercive organisations (such as prison services and the armed forces) are particularly "at risk" and in need of support and education about human rights.

The terms of reference of the working party led it beyond torture to judicial punishment, the trade in human organs, and experimentation on prisoners. Medicine Betrayed makes no distinction-as the Torture Report did-between torture and judicial corporal punishment. The participation of doctors in inflicting pain and suffering is regarded in the same way: as a breach of the doctors' ethical obligations to the patient. The working party did not sidestep controversial issues of human rights in Britain - such as the detention of asylum seekers, the use of the Prevention of Terrorism Act, and the ill treatment of detainees in Northern Ireland - which gives the report special credibility.

The late John Dawson, who stimulated the BMA's interest in this topic, suggested the use of the term "indicator" to describe potential threats to the protection of human rights. ${ }^{+}$ Indicators "point to a situation where the abuse of human rights can more easily occur or be covered up." They include emergency legislation permitting detention without trial, the denial of detainees' rights to see a lawyer or doctor on request, and the absence of clinical independence for prison doctors. To contribute to the preservation of democratic freedom doctors need to keep an ever watchful eye on the state.

Medicine Betrayed provides extremely useful guidance for doctors (and others) in monitoring human rights. Its recommendations are unambiguous: "if the possibility of abuses of human rights comes to the attention of a medical practitioner, they have an ethical duty to take immediate action." The international medical community is urged to "encourage effective opposition to torture in countries where the pressure for medical participation is considerable." The working party was "negatively struck by the number of examples of false, inadequate and absent forensic statements" about torture related incidents. It recommends that medical associations should investigate failures of forensic specialists to document torture adequately and support forensic staff who are under pressure to falsify their findings.

The working party recommends that doctors should not participate in corporal punishment, either by certifying fitness or by performing amputations, and that professional associations and individual doctors should make clear their opposition to such punishments. The Declaration of Tokyo's position on hunger strikes is reaffirmed: it states that "where a prisoner refuses nourishment and is considered by the doctor 
as capable of forming an unimpaired and rational judgment concerning the consequences of such a voluntary refusal of nourishment, he or she shall not be fed artificially."

From a European viewpoint, it is hard to imagine the importance of reports such as Medicine Betrayed for colleagues working to protect human rights in less privileged conditions. During several human rights missions I have seen how the BMA's Torture Report is used as an authoritative reference when violations of human rights are challenged.

The working party approaches the future realistically, encouraged by the progress already made in human rights. Implementing its recommendations now becomes a responsi- bility of the international medical and human rights community. After Medicine Betrayed doctors cannot remain silent.

Johannes Wier Foundation,

ADRIAAN VAN ES

PO Box 1551,

3000 DN Amersfoort,

Netherlands

1 BMA. Torture report. London: BMA, 1986.

2 Medicine betrayed: the participation of doctors in human rights abuses. London: BMA, Zed Books, 1992. 3 Lifton RJ. The Nazi doctors: medical killing and the psychology of genocide. London: Papermac, 1986

4 Amnesty International Medical Commission, Marange V. Doctors and Torture; Collaboration or Resistance? London: Bellow, 1991:142-5.

\section{The death penalty}

\section{When doctors must say no}

Although largely abolished within the European Community, the death penalty is retained by more than 100 nations. ${ }^{1}$ In the United States 36 states and the federal government prescribe capital punishment for aggravated murders, and more than 2600 prisoners are now under sentence of death. ${ }^{2}$ In the paradoxical quest for humane methods of execution 21 American states now use lethal injection. ${ }^{2}$ Appropriation of a medical technology for extinguishing life has provoked intense discussion of ethical issues surrounding medical involvement in capital punishment. . $^{3-6}$

Participation by doctors in legally authorised executions was declared unethical by the American Medical Association's council on ethical and judicial affairs in 1980 and by the World Medical Association the next year. Last December the American Medical Association's house of delegates asked the council on ethical and judicial affairs to clarify the scope of forbidden participation, ${ }^{7}$ and a report is expected later this year.

Recently a working party of the BMA issued a report on physicians and human rights, ${ }^{8}$ which endorses the view that medical ethics forbids not only the act of injecting the lethal substance but also any complicity in the execution process. This might include selecting the injection sites, starting intravenous lines, choosing the drug, and giving technical advice during the lethal procedure. Although certification of death is a normal part of medical duties, the working party strongly recommends that this should take place away from the site of execution so that the doctor need not be present at the execution.

Discussions of this problem often begin with the principle of "first do no harm," but it is a mistake to derive a prohibition against medical participation in executions from this ethical injunction. Medical consultation about carrying out executions or any other lawfully imposed punishment can help to avoid unnecessary pain and suffering to the prisoner. Indeed, because unnecessary suffering in the administration of punishment violates human rights it can be argued, paradoxically, that medical involvement in capital punishment actually promotes human rights.

An analogous dilemma arises in connection with corporal punishments and deprivations suffered by prisoners in confinement. Some penalties are so cruel and degrading as to violate prevailing standards of human rights, and it would of course be unethical for anyone, including doctors, to participate in such practices. As the BMA's Handbook on Medical
Ethics observes, for example, "any diet so restricted that medical monitoring is necessary ... is inhuman, and no doctor should be associated with it." Some painful punishments, however, such as isolation in dark cells and whipping, are not categorically prohibited under prevailing standards of human rights and persist in many parts of the world; medical assessment of a prisoner's fitness for these punishments and medical monitoring of their administration can prevent injury and suffering more extreme than intended or legally authorised. It is therefore specious to claim that "first do no harm" compels doctors to abstain from these practices. If the ethical permissibility of medical participation turns on its effects (on the wellbeing of prisoners) as compared with the effects of non-participation the ethical argument will at best be inconclusive.

Why then is medical participation in otherwise lawful administration of corporal and capital punishments properly regarded as unethical? The answer lies not in the logic of therapeutic ethics but rather in the fundamental idea that serving as an agent of the state's punitive apparatus is an unacceptable social role for a doctor. Medical participation tends to "make doctors the arbiters of painful or lethal punishments." Doctors hold their medical knowledge in trust for the collective wellbeing of mankind, and they must guard against the exploitation of that knowledge in ways that compromise the supreme aspirations of the profession. This is why doctors' position must be that their unique knowledge and skills should not be used to effect the punitive aims of the state, either in deciding whether a particular punishment should be carried out or in directing how it should be administered.

Participation in the administration of punishment should be distinguished, however, from participation in the administration of justice through forensic evaluation and testimony. In general, medical testimony in legal proceedings is not ethically problematic because it contributes to the fair and accurate resolution of disputes and in this way promotes collective wellbeing. Testimony in criminal cases can, of course, increase the probability of the defendant's conviction or aggravated punishment, but medical participation in criminal proceedings has never been regarded as ethically problematic if the expert maintains objectivity and independence and does not stray beyond the boundaries of medical knowledge. ${ }^{1011}$ Capital prosecutions do not differ in this respect from other criminal cases. (It would surely be difficult 